\title{
COMPARATIVE STUDY OF SELF-COMPACTING CONCRETE CONTAINING LIGHTWEIGHT AND NORMAL AGGREGATES
}

\author{
Ramamohanrao PANNEM ${ }^{1 *}$, Padmaja P. KUMAR ${ }^{2}$
}

\begin{abstract}
Based on the available literature, a simple method was adopted to calculate the packing density of aggregates and thereby reduce their void content by optimising their packing aggregates and by using two different sizes of coarse aggregates and fine aggregates. This study provides an understanding of the way in which the shape of aggregates affects the properties of self-compacting concrete (SCC). The fresh, hardened, and durable properties of SCC with normal and lightweight fly ash coarse aggregates are found at the corresponding age of the curing. Their values were compared with respect to SCC containing normal aggregates. A mix with fly ash aggregates was found to have better fresh concrete properties due to the round shape of the aggregates. After the packing of the aggregates, this mix was found to have better mechanical and durability properties than all the other concrete mixes.
\end{abstract}

\section{Address}

1 Centre for Disaster Mitigation and Management, VIT,Vellore, India

2 Dept. of Civil Engineering, VIT, Vellore, India

* Corresponding author: ramamohanrao71@gmail.com

\section{Key words}

- Lightweight fly ash coarse aggregates,

- Optimisation,

- Packing density.

\section{INTRODUCTION}

Self-compacting concrete is a concrete which can flow under its own weight without segregating and can fill formwork as well as spread into any reinforcement without providing any mechanical vibration or compaction. In order to have durable structures, proper compaction should be provided, but due to the lack of workmanship, the quality of the construction is affected. It was decided to produce a new type of concrete that could spread freely without any consolidation called "self-compacting concrete" (SCC); this was first suggested by H. Okamura in 1986. Workability studies were later proposed by H. Ozawa and K. Maekawa in 1988 at the University of Tokyo. The voids are said to be the origin of concentrated stress; therefore, by reducing the voids, the particles' packing density can be improved. Monosized particles tend to produce more voids; hence paste is required to fill the voids, and the extra paste required to produce flowability will be greater. Therefore, a basic principle in the packing phase of aggregates is to reduce voids, so that a lot more paste is available for flowability. In this study, two different sizes of coarse aggregates have been mixed with fine aggregates and the packing density calculated. The void content was calculated from the packing density, the paste content was optimised from the trials.

\subsection{Literature review}

A simple mix design for producing good quality SCC for medium - strength concrete was first developed by Nan Su, with fine aggregates of $54-60 \%$ (Su abd Miao, 2003). Later on, this method was modified to have a low cement content, so that the packing factor was calculated first and then cementitious materials were filled into the voids (Priyadharshini et al., 2011). There are some variations in the dry packing density that was obtained and the packing density obtained from different packing models. This variation can be reduced by using a wet packing method that has been used to determine the packing density of fine blended aggregates under wet conditions; the packing density was found to be higher than that obtained with dry packing (Nanthagopalan and Santhanam, 2012). SCC designed and produced with the proposed mix design method contains more sand but fewer coarse aggregates; thus its ability to pass through reinforcement gaps can be enhanced (Su et al., 2001). 
The properties of fresh concrete with the same packing density depend on the selection of the proportion of the aggregates, and the mechanical properties are not affected. Larger variations in the void ratio are influenced by the packing of the aggregates and small variations by the powder phase. A simple method to obtain packing density was proposed, and a ternary packing diagram was developed by MATLAB (Nanthagopalan and Santhanam, 2012). For optimising the paste, they conducted a Marsh cone test and a mini slump test to finalise the admixture and cement quantities; the granular skeleton was optimised by the methods in ASTM C29 (Rodriguez, 2015). Over the years, the application of lightweight self-compacting concrete (LSCC) has rapidly progressed in the reduction of the dead load of the overall structure, so that the main concern relating to LSCC is the consumption of lightweight aggregate, which is usually lower in density coupled with high porosity (Kwan and Fung, 2009). A mix with only lightweight aggregate at a ratio of $75 \%$ showed a $7 \%$ increase in structural efficiency compared to the control concrete, while a mix with $100 \%$ showed a $20 \%$ decrease in its structural efficiency (Choi et al., 2006). The compressive strength of self-consolidating concrete at 28 days with up to $75 \%$ of lightweight coarse aggregate was about $10 \%$ lower than the control concrete. For SCC with a $100 \%$ lightweight coarse aggregate replacement, the compressive strength was $20 \%$ lower than the control concrete. (Kim et al., 2010)

\subsection{Significance of the Research}

The cement industry alone contributes to $7 \%$ of the carbon dioxide released into the atmosphere. These anthropogenic activities result in the greenhouse effect and global warming. One solution to this problem is to reduce the use of cement by replacing some part of the cement with cementitious materials such as ground granulated blast furnace slag (GGBS), silica fume (SF) or fly ash (FA). SCC mixes include large quantities of powder content so that the required paste can provide the required flowability. By introducing a new concept such as packing density, the powder content can be optimised. The main focus of this study is to introduce the concept of packing density to improve the properties of self-compacting concrete and optimise the consumption of cement and supplementary cementitious materials. With the production of economical and sustainable concrete, the paste content can thereby be reduced, which results in less shrinkage.

\section{MATERIALS}

\subsection{Binder materials}

OPC53 grade cement with a specific gravity of 3.15 was used In the present study, $50 \%$ of the cement was replaced with supplementary cementitious materials, i.e., $35 \%$ of GGBS and $15 \%$ SF. The ground granulated blast furnace slag (GGBS) and silica fume (SF) were procured from Astra Chemicals. The specific gravity of the slag and silica fume is 2.85 and 2.63 respectively.

\subsection{Normal aggregates}

Coarse aggregates of two different sizes, i.e., 20-12.5 mm with a specific gravity of 2.66 and $12.5-10 \mathrm{~mm}$ with a specific gravity of 2.69 were used in this study. Fine aggregate (river sand) from a local source with a size of less than $2.36 \mathrm{~mm}$ was used in the concrete.

\subsection{Lightweight aggregates}

Class F fly ash was used for the preparation of the fly ash coarse aggregates. The pellets were sieved, and aggregates sized 20-12.5 $\mathrm{mm}$ with a specific gravity of 1.426 and sized $12.5-10 \mathrm{~mm}$ with a specific gravity of 1.463 were used for this study.

\subsubsection{Preparation of fly ash pellets}

Based on the curing regime, there are three methods for the preparation of lightweight aggregates, i.e., sintering, autoclaving, and cold bonding techniques. To prepare the pellets, $2 \% \mathrm{Ca}(\mathrm{OH})_{2}$ and $8 \%$ cement are added to the fly ash by weight. Then the fly ash and binder are dry mixed for 2 minutes, and $22 \%$ of water with $\mathrm{Ca}(\mathrm{OH})_{2}$ is sprayed into it. The pellets are formed after 30 minutes. The fresh pellets were collected and kept at room temperature for 24 hours and cured for 28 days. Calcium hydroxide is added because it reacts with the silica present in the fly ash and produces C-S-H gel, which contributes to a better initial strength and an improved rate of hydration and agglomeration (Wua et al., 2009)

\subsubsection{Tests on aggregates}

To determine the impact and abrasion values of the coarse aggregate, aggregate impact and abrasion tests were conducted on the natural and fly ash aggregates. The tests showed that the aggregate impact value was found to be $16.2 \%$ and $39.037 \%$ for the natural and fly ash aggregates respectively and that this value is less than $45 \%$ (permissible value as per IS: 383 - 2016 (IS 383-1970)). The aggregate abrasion value was found to be $22.3 \%$ and $99 \%$ respectively for the natural and fly ash aggregates. According to the test values, the abrasion value exceeds the permissible value of $60 \%$ for fly ash aggregate.

\subsection{Superplasticizer}

Auramix 400 is a polycarboxylic ether-based superplasticizer used in SCC in accordance with IS 9103 - 1999 (IS 1903- 1999). It was supplied by FORSOC Chemicals, Bengaluru. The density of the superplasticizer is $1.09 \mathrm{~kg} / \mathrm{L}$, and it contains a $4 \%$ viscosity modifying agent.

\section{EXPERIMENTAL PROGRAMME}

In this study, 20-12.5 mm aggregates were used in the control mix, which was compared with the SCC after optimising the aggregate content but with the same paste content as normal SCC. Then the SCC was mixed after optimisation of the paste was obtained from different trials. SCC with lightweight aggregates was also prepared.

\subsection{Packing of Aggregates}

For optimising the aggregates, the experimental packing density of the aggregates was calculated (Kwan and Fung, 2009), and the following procedure was adopted: 


\subsubsection{Procedure}

First, the weight of the coarse aggregate and sand was taken; a $10 \mathrm{~L}$ container was filled as shown in Fig.1. The coarse and fine aggregates were selected in different proportions of volume and were mixed manually till they became a proper blend. The blend was added to the container, and then a trap door was opened. An $8 \mathrm{~L}$ container kept below the $10 \mathrm{~L}$ container was filled instantaneously; after it was levelled; it was weighed, and the bulk density and packing density were calculated.

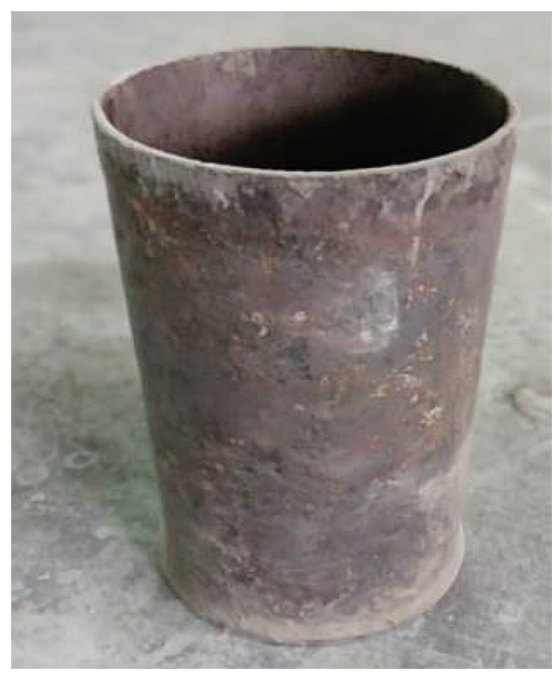

Fig. 1 Aggregate measurement container

The bulk density for the different proportions of the aggregate was obtained and calculated as the total weight by the volume of the container. Similarly, the packing density of the different proportions of the aggregates is shown in equation (1):

$$
\text { Packing Density }=\left(\frac{M 1}{G 1}+\frac{M 2}{G 2}+\frac{M 3}{G 3}\right) \times \frac{1}{V}
$$

Void Content $=1-$ Packing Density

Where: $M_{1}, M_{2}, M_{3}$ - weight of each aggregate, $G_{1}, G_{2}, G_{3}$ - Specific gravity of different aggregates, $\mathrm{V}-$ Volume of the container.

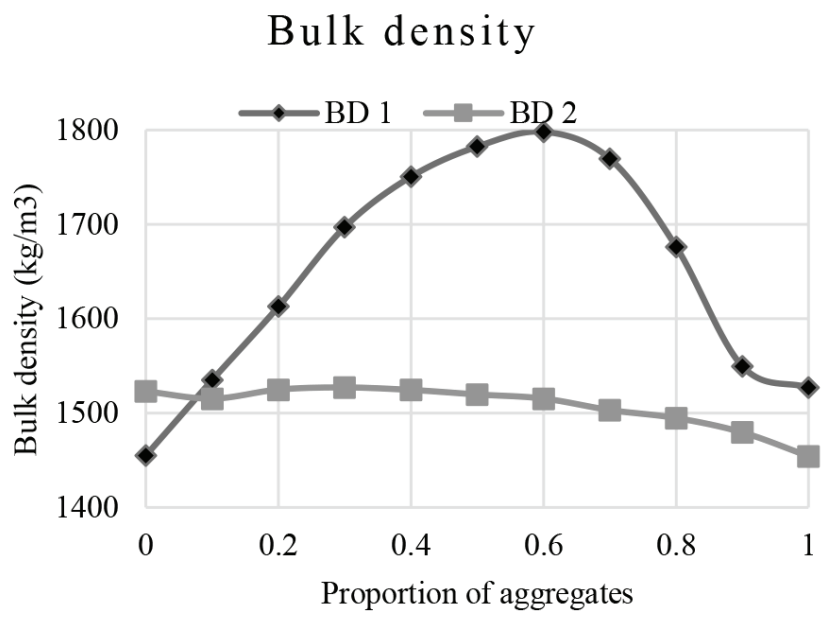

Fig. 2 Bulk density of aggregates
Packing density

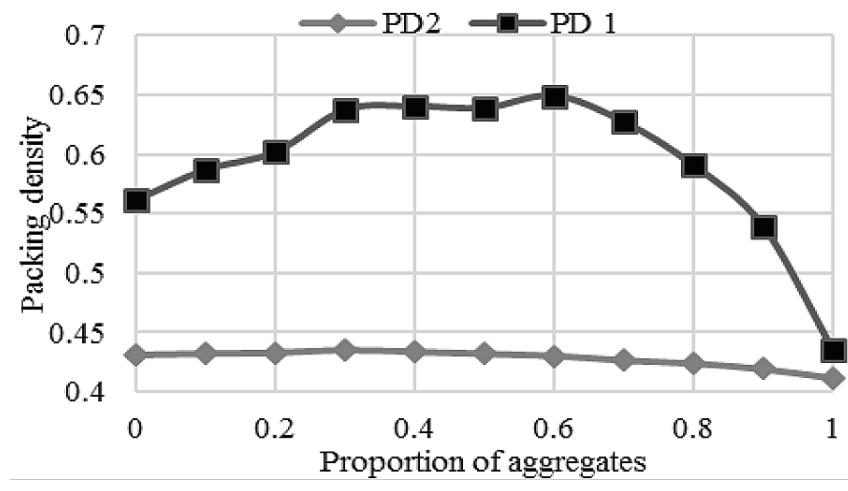

Fig. 3 Packing density of aggregates

BD1, PD1, and VC1 indicate the bulk density, packing density, the void content of the coarse aggregates, and sand. The bulk density of the aggregates is shown in Fig. 2, which shows that the bulk density 2 (BD2) represents the highest density value. The minimum void content for the two coarse aggregates was at a proportion of 70-30 and was found to be 0.5652 as shown in Fig 3. After mixing the sand in this mixture in different proportions, the void content was found to be 0.3508 at a proportion of 60: $40 \%$ (CA: FA); of the 60 percent coarse aggregates, 70 percent was $20-12.5 \mathrm{~mm}$ aggregates, and 30 percent was $12.5-10 \mathrm{~mm}$. The packing density of the aggregates is shown in Fig. 4, and the experimental values of the packing density determined are also shown in Fig. 5.

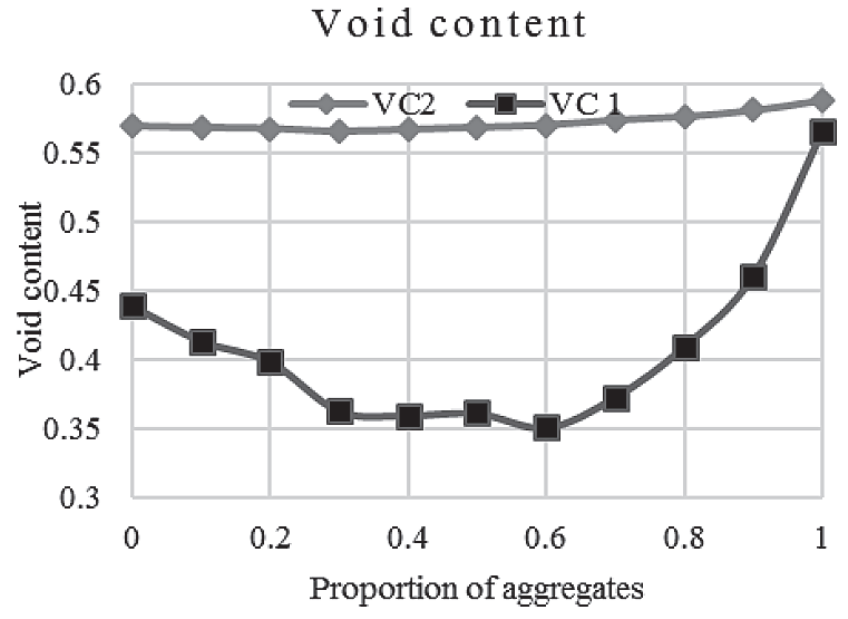

Fig. 4 Void content of aggregates

\subsection{Mix design of the SCC mixes}

The modified Nan - Su method was used to design the control mix of M 25 grade concrete using 20-12.5 mm size aggregates. As per ACI 237R -07 (ACI, 2017), the permissible limit for the water-to-cement $(\mathrm{w} / \mathrm{cm})$ ratio for the self-compacting concrete was in a range of 0.32 to 0.40 . Several trial mixes were cast with $\mathrm{w} / \mathrm{cm}$ ratios of 0.32 , 0.325 , and 0.33 respectively. A second mix (PDSC) was adopted after incorporating the packing of the aggregates; this mix was designed with the same paste content as the NSC (w/cm 0.325). Subsequently, several trials were carried out with different $\mathrm{w} / \mathrm{cm}$ ratios. 


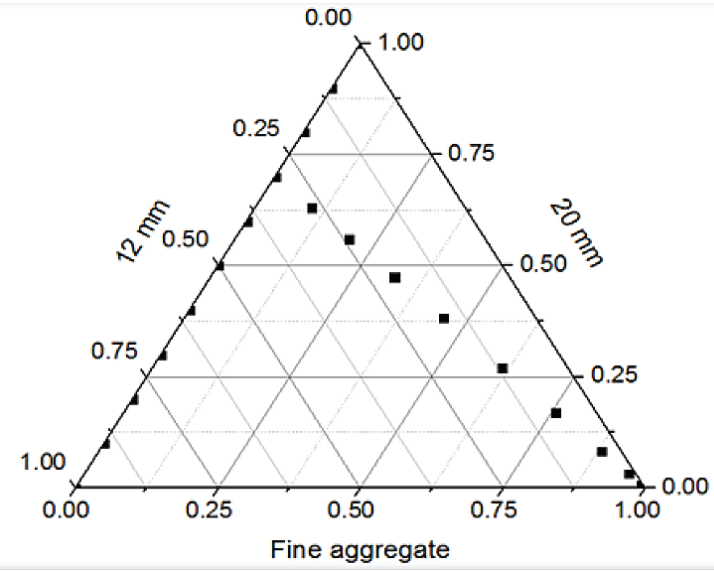

Fig. 5 Experimental points for determining the packing density

\subsubsection{Optimisation of the paste content}

The paste included the binder materials, superplasticizer, and water. A third mix (OPSC) was adopted after the optimisation. For the first trial to obtain this mix, the paste content was roughly calculated from equation (2). The air content in the mix was assumed to be about $1.8 \%$, as per ACI $237 \mathrm{R}-07$ (ACI, 2017); the air content was be $0-2 \%$ after substituting these values in equation (2) and adding $1 \%$ extra paste for flowability. The paste content obtained was therefore $33 \%$.

Paste content $=1-$ Packing density - Air content $+(1-4 \%)$

According to the guidelines given in ACI 237R - 07 (ACI, 2017), the paste content should vary from $34-40 \%$. For the first trial mix, the paste content adopted was $35 \%$. Trials were carried out with varying paste contents and mixed with a $36 \%$ paste content for proper flowability, filling ability and passing ability as an optimised paste. The fourth mix (FDSC) was SCC with two different fly ash aggregates mixed in the same proportion as that of normal aggregates, i.e., a 60:40 proportion of the fly ash aggregates and sand. Of the 60 percent fly ash aggregates, 70 percent of the fly ash aggregates were $20-12.5 \mathrm{~mm}$, and 30 percent were $12.5-10 \mathrm{~mm}$. The paste content was maintained the same as normal SCC for calculating the mix design of the FDSC. The details of the proportions of the different mixes are shown in Tab.1.

\subsection{Concrete Mix Procedure}

The aggregates and powder materials were first added to a mixer; dry mixing was then carried out for 2 minutes. After the proper blending of this mixture, around one fourth of the total water was added initially into the mixer and then blended. Subsequently, the rest of the water with the superplasticizer was added to the mix, which continued to be blended for about 5 minutes. When using fly ash aggregates in a mix, they should be soaked in water for 30 minutes and then dried at room temperature prior to being mixed with the other ingredients inside a concrete mixer.

When selecting the control mix, the mix with a $\mathrm{w} / \mathrm{cm}$ ratio of 0.32 could not provide the required slump flow as per ACI $237 \mathrm{R}$ 07 . Moreover, the mix with a $\mathrm{w} / \mathrm{cm}$ ratio of 0.33 showed signs of segregation, so a mix with a w/cm ratio of 0.325 was tested, and an appropriate slump was obtained; hence this mix was selected as the control mix.

\section{CONCRETE PROPERTIES}

Tab. 2 provides the information about the fresh concrete properties of all the concrete mixes adopted in this study. All the mixes have test values within the limit as per EFNARC (IS13311-1992) except for segregation resistance, i.e., V funnel T5 minutes (s).

Tab. 2 Fresh Concrete Properties

\begin{tabular}{|c|c|c|c|c|c|c|}
\hline Tests & Property & NSC & PDSC & OPSC & FDSC & $\begin{array}{c}\text { EFNARC } \\
\text { Limit }\end{array}$ \\
\hline $\begin{array}{c}\text { Slump flow } \\
(\mathrm{mm})\end{array}$ & $\begin{array}{c}\text { Filling } \\
\text { ability }\end{array}$ & 692.5 & 723 & 683.5 & 782.5 & $650-800$ \\
\hline T $50(\mathrm{~s})$ & $\begin{array}{c}\text { Filling } \\
\text { ability }\end{array}$ & 4.6 & 4.93 & 4.95 & 4.03 & $2-5$ \\
\hline J ring (mm) & $\begin{array}{c}\text { Passing } \\
\text { ability }\end{array}$ & 8.2 & 8.7 & 5.5 & 9.3 & $0-10$ \\
\hline VSI & $\begin{array}{c}\text { Stability } \\
\text { L }\end{array}$ & 1 & 0 & 2 & $0-2$ \\
\hline L box (h/ $\left./ h_{1}\right)$ & $\begin{array}{c}\text { Passing } \\
\text { ability }\end{array}$ & 0.82 & 0.88 & 0.84 & 0.92 & $0.8-1.0$ \\
\hline V funnel (s) & $\begin{array}{c}\text { Filling } \\
\text { ability }\end{array}$ & 11.36 & 10.63 & 11.21 & 7.32 & $6-12$ \\
\hline $\begin{array}{l}\text { V funnel T5 } \\
\text { minutes (s) }\end{array}$ & $\begin{array}{c}\text { Segregation } \\
\text { Resistance }\end{array}$ & 14.03 & 11.89 & 13.24 & 9.96 & $0-3$ \\
\hline
\end{tabular}

\subsection{Mechanical Properties}

The mechanical properties of the concrete such as the compressive strength, the splitting tensile strength at 7, 14 and 28 days, and the flexural strength at 28 days were determined and are discussed below.

The concrete specimens of $100 \times 100 \times 100 \mathrm{~mm}$ specimens were cast and allowed to cure for different periods, i.e., 7,14, and 28 days. A ccompressive strength test was conducted on the cubical specimens

Tab. 1 Mix Proportion of various mixes

\begin{tabular}{|c|c|c|c|c|c|c|c|c|}
\hline \multirow{2}{*}{ Mix } & \multirow{2}{*}{$\begin{array}{l}\text { Cement } \\
\left(\mathrm{kg} / \mathrm{m}^{3}\right)\end{array}$} & \multirow{2}{*}{$\begin{array}{c}\text { GGBS } \\
\left(\mathrm{kg} / \mathrm{m}^{3}\right)\end{array}$} & \multirow{2}{*}{$\begin{array}{c}\mathrm{SF} \\
\left(\mathrm{kg} / \mathrm{m}^{3}\right)\end{array}$} & \multirow{2}{*}{$\begin{array}{c}\text { Water } \\
\left(\mathrm{kg} / \mathrm{m}^{3}\right)\end{array}$} & \multirow{2}{*}{$\begin{array}{l}\text { SP } \\
(1)\end{array}$} & \multicolumn{2}{|c|}{$\mathrm{CA}\left(\mathrm{kg} / \mathrm{m}^{3}\right)$} & \multirow{2}{*}{$\begin{array}{c}\text { Sand } \\
\left(\mathrm{kg} / \mathrm{m}^{3}\right)\end{array}$} \\
\hline & & & & & & $20-12.5 \mathrm{~mm}$ & $12.5-10 \mathrm{~mm}$ & \\
\hline NSC & 343 & 240 & 103 & 223 & 2.2 & 629 & - & 814 \\
\hline PDSC & 344 & 241 & 103 & 220 & 2.2 & 421 & 174 & 847 \\
\hline OPSC & 318 & 223 & 95 & 207 & 2.91 & 427 & 183 & 915 \\
\hline FDSC & 291 & 203 & 87 & 186 & 2.66 & 341 & 146 & 732 \\
\hline
\end{tabular}




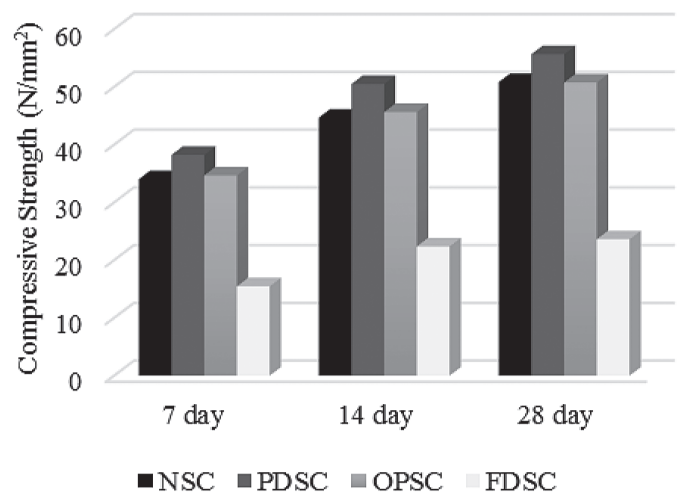

Fig. 6 Compressive strength values

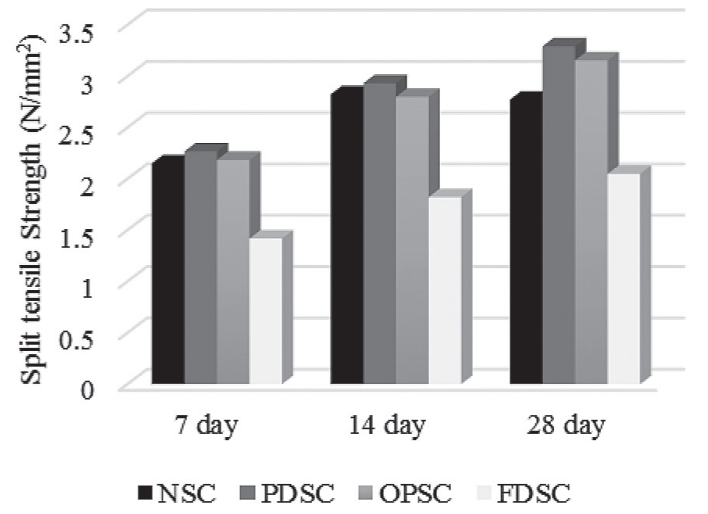

Fig. 7 Splitting tensile strength values

for all the mixes at 7, 14 and 28 days of curing as per IS 516 (IS: 5161991) The specimens were loaded in a compressive testing machine for the maximum load. The average compressive strength for the normal and lightweight concrete specimens is shown in Fig. 6. It was conducted on concrete cylinder specimens with a size of $100 \mathrm{~mm}$ diameter and a length of $200 \mathrm{~mm}$ at different stages of the curing. A splitting tensile strength test was conducted on the specimens for all the concrete mixes at 7,14 and 28 days of curing as per IS 5816 (IS: 5816-1999). The average tensile strength for the normal and lightweight concrete specimens are shown in Fig. 7. The flexural strength test was conducted on three concrete beam specimens of a size of 100 $\mathrm{mm} \times 100 \mathrm{~mm} \times 500 \mathrm{~mm}$ at 28 days for each concrete mix as per IS 516 (IS: 516-1991) and are shown in Fig. 8.

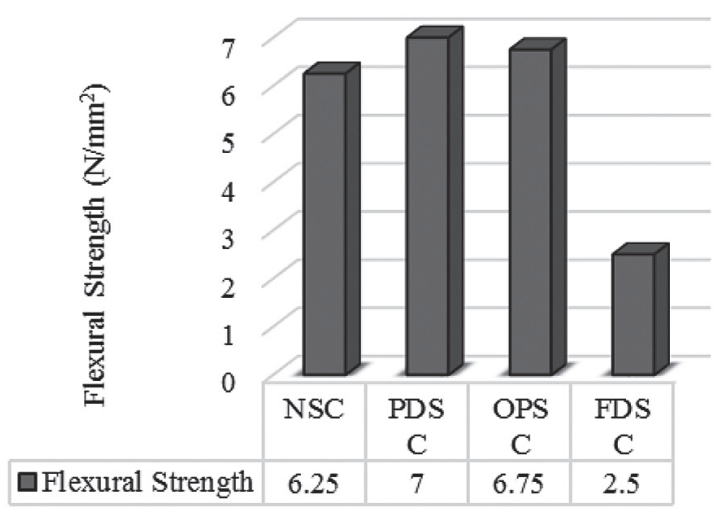

Fig. 8 Flexural strength of the 4 mixes at 28 days of curing
The 28-day compressive, splitting tensile and flexural strength tests are the maximum for PDSC and were found to be 55.65, 3.29 and $7 \mathrm{~N} / \mathrm{mm}^{2}$ respectively, because the packing of the aggregates improved the mechanical properties of the concrete. After the optimisation of the fly ash mix paste, it had better properties than the control mix. The FDSC mix has less strength because the fly ash pellets had less strength.

\subsection{Durability Properties}

\subsubsection{Water Absorption tests and Sorptivity}

Cubic specimens sized $100 \times 100 \times 100 \mathrm{~mm}$ were cast and cured for 28 days. After the curing, these specimens were removed from the curing tank. After the surface drying of the specimens, their weight was noted. These specimens were kept in an oven for 24 hours at 105 $-110^{\circ} \mathrm{C}$ and then cooled to the room temperature. The weight of the specimens was noted. The specimens were then kept immersed in water for 24 hours; the weight was measured again after wiping the water from the specimens. The water absorption calculated is given in equation (3):

$$
\text { Water absorption }=\frac{W 2-W 1}{W 1} \times 100
$$

Where: W1 - oven dry weight in g, W2 - weight after immersing in water in $\mathrm{g}$.

The water absorption values of the mixes are shown in Fig. 9. The concrete mixes showed a lower absorption value than observed in Fig. 9. In the case of sorptivity, the specimen with a $100 \mathrm{~mm}$ diameter and $50 \mathrm{~mm}$ height was oven dried for 24 hours, covered with sealant, and placed in water for 5 hours. Changes in its weight were noted every 0.5 hours. The sorptivity values of all the mixes are shown in Fig. 10. The sorptivity and cumulative water absorption values of the specimens were calculated as per equations (4) and (5):

$$
\begin{gathered}
S=\frac{I}{t^{0.5}} \\
I=\frac{W 2-W 1}{\mathrm{Ad}}
\end{gathered}
$$

where: $\mathrm{W}_{2}$ - weight of specimen after absorption in $\mathrm{g}, \mathrm{W} 1$ - Oven dry weight in $\mathrm{g}, \mathrm{t}$ - Elapsed time in minutes, $\mathrm{A}$ - Surface area of specimen through which water can penetrate in $\mathrm{mm}^{2}, \mathrm{~d}$ - density of water in $\mathrm{g} / \mathrm{mm}^{3}$, $\mathrm{S}$ - Sorptivity in $\mathrm{mm}, \mathrm{I}$ - Cumulative water absorption.

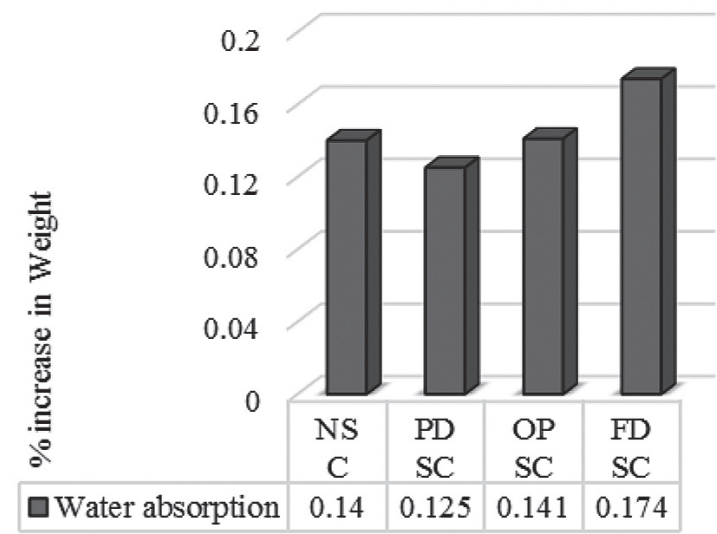

Fig. 9 Water absorption values for concrete mixes 


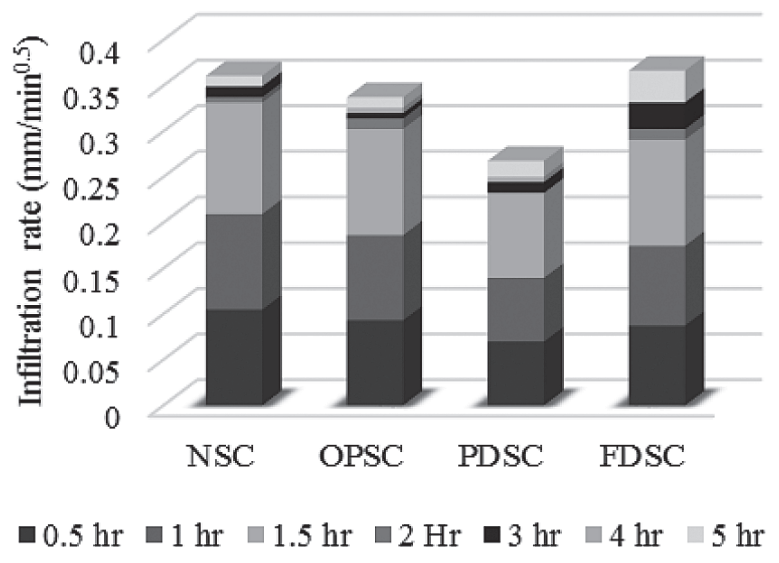

Fig. 10 Sorptivity values for concrete mixes

\subsubsection{Acid Resistance}

Cubes sized $100 \times 100 \times 100 \mathrm{~mm}$ were cast and cured for 28 days. The specimens were dried and then placed in $2 \% \mathrm{H}_{2} \mathrm{SO}_{4}$ according to the weight of the water. These specimens were removed from the acidic solution, and the weight of the specimens was measured at 7 , 14, and 28 days. The compressive strength of the specimen at 28 days was measured, as is shown in Fig.11; the percent loss in the compressive strength of the concrete specimens at 28 days is shown in Fig. 12. Equations (6) and (7) were used for calculating the loss in weight of the compressive strength of the concrete specimens.

$$
\begin{gathered}
\% \text { Loss in weight }=[\mathrm{W} 1-\mathrm{W} 2 / \mathrm{W} 1] 100 \\
\% \text { Loss in weight }=[\mathrm{S} 1-\mathrm{S} 2 / \mathrm{S} 1] 100
\end{gathered}
$$

Where: W1 - Weight of specimen after 28-day curing in g, W2 - Weight of specimen after immersing in acid in g, S1 - Strength of specimen after 28-days of water curing, S2 - Strength of specimen after immersing in acid in $\mathrm{g}$.

\subsection{Ultra-Sonic Pulse Velocity Test}

The ultra-sonic pulse velocity (UPV) test is used to determine the integrity of concrete and to measure other physical properties that influence wave propagation. It is a useful technique for quality control and can be used to detect defects, measure thickness, or characterize

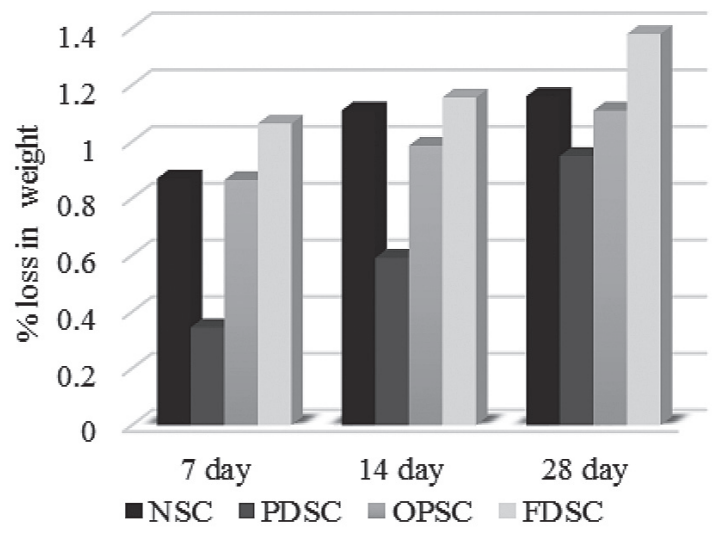

Fig. 12 Weight loss (\%) of concrete specimens at 28 days

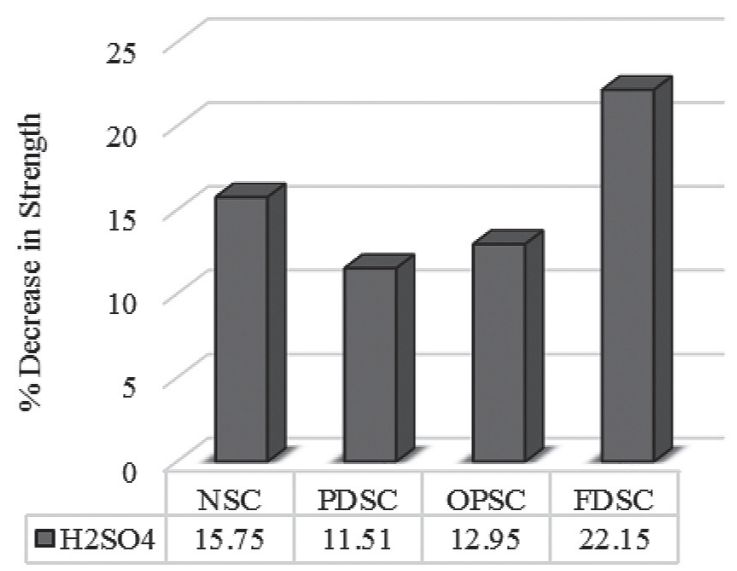

Fig. 11 Decrease in compressive strength of the concrete specimens

the materials in concrete. The length of the specimen has to be fixed in a digital meter before testing the specimen. The transducers are connected through wire cords from the digital meter, and lubricant is applied on the two transducers so they can have sticky contact with the concrete specimen or surface. The transducers are placed on either side of the specimen, and the digital meter is turned on to send a pulse wave through the specimen. The time of travel of the pulse wave through the specimen is noted, and the average velocity of the pulse wave is calculated using the formula:

Pulse velocity $=$ Path length $/$ Travel time

Ultrasonic pulse velocity tests were conducted on the different concrete mix specimens at 28 days of curing to test the homogeneity/quality of the concrete. If the pulse velocity is $>4.5 \mathrm{~km} / \mathrm{s}$, then the quality of concrete is considered excellent; if it is $3.5-4.5$, then the concrete is good. Similarly, if the velocity is $3.0-3.5 \mathrm{~km} / \mathrm{s}$, the concrete is satisfactory, but a loss of integrity is present; on the other hand, if the velocity is $<3.0 \mathrm{~km} / \mathrm{s}$, then the concrete specimen is of poor quality as per the guidelines given in IS: 13311 (Part 2)-1992 (IS13311-1992). The UPV test values are shown in Fig. 13. The FDSC concrete mix exhibited poor quality as per the velocity reading, but the remaining mixes showed a good quality. The packing was good when compared to the FDS concrete mix specimens.

\subsection{XRD Analysis}

A powder diffractometer that uses $\mathrm{Cu} \mathrm{K} \alpha$ radiation at $40 \mathrm{KV}$ and $30 \mathrm{~mA}$ was used for recording the XRD data with a range of measurement of $5-60^{\circ}$. A powdered sample exceeding $75 \mu \mathrm{m}$ was used in the

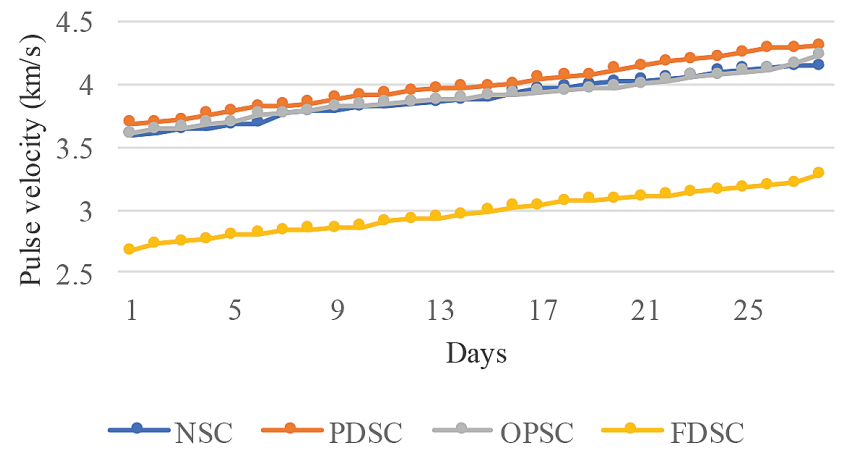

Fig. $13 U P V$ test values at different stages of curing 


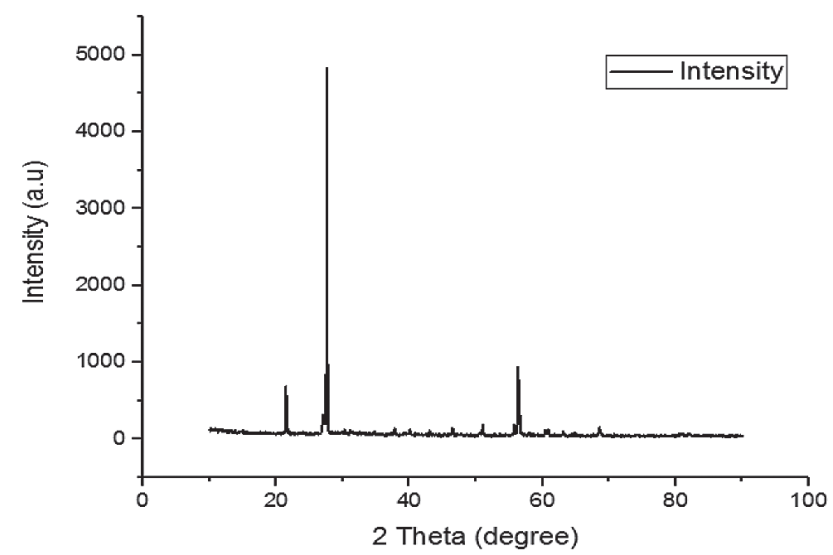

Fig. 14 Variation of intensity of different elements in FDSC

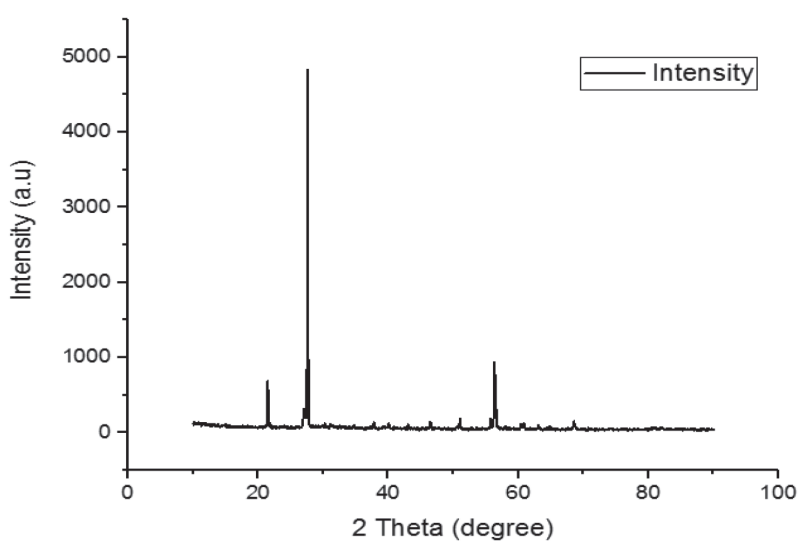

Fig. 16 Variation of intensity of different elements in NSC

XRD analysis. The XRD analysis of all the concrete mixes is shown in Figs. 14 to 17.

For the PDSC, OPSC and FDSC specimens, the peak was observed at 2 theta of $27^{\circ}$, which indicates that there is a high presence of silica in the sample and that its structure is crystalline in nature. For the OPSC specimen there was a slight presence of anhydrite. The FDSC sample had CSH present. It was observed that the major component present in the sample was silica content due to the peak of a 2 theta angle of $27^{\circ}$. The peak indicates that the silica content is of a crystalline nature.

\section{CONCLUSIONS:}

Based on the limited experiments conducted on the SCC with normal and lightweight aggregates, the following conclusions were drawn:

- The FDSC mix is a less stable mix with a slight aggregate pile in the centre; the OPSC and NSC mixes are highly stable as there is no segregation. The PDSC mix is also stable as there is no aggregate pile at the centre of the slump flow.

- The concrete mix with fly ash aggregates has less stability than the mix packed with normal aggregates.

- The mechanical properties of the mix with fly ash aggregates were slightly lower than the normal mix, and the PDSC mix showed increases in the compressive, split tensile, and flexural strength of $9.5 \%, 18.77 \%$, and $12 \%$ respectively, compared with the normal mix.

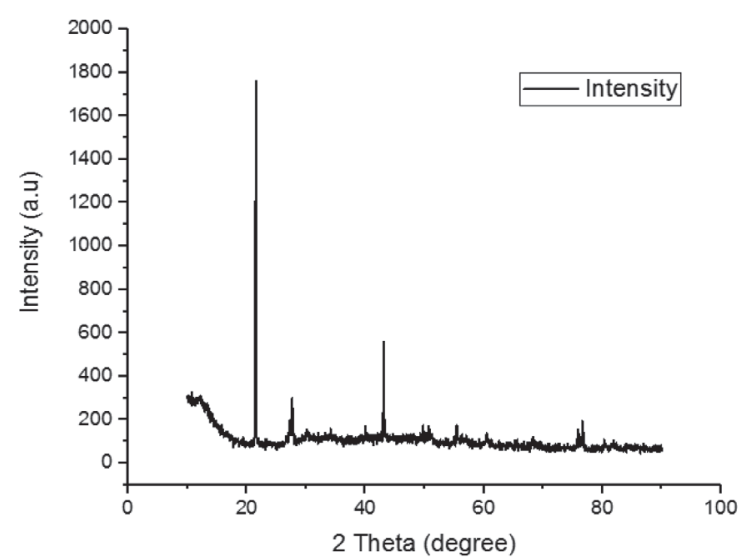

Fig. 15 Variation of intensity of different elements in OPSC

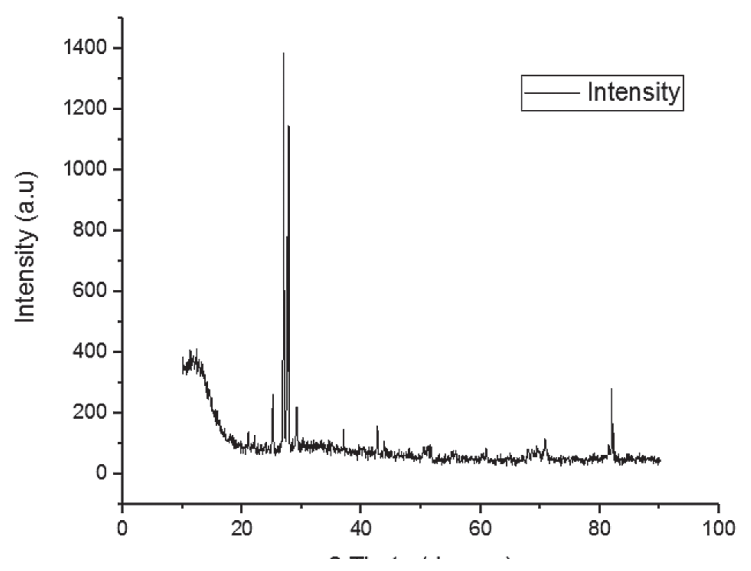

Fig. 17 Variation of intensity of different elements in PDSC

- After the packing of the aggregates, the concrete mixes with the same paste content showed an improvement in their fresh, hardened and durability properties.

- The low UPV values for the FDSC indicate the presence of voids in the concrete specimens. The PDSC specimen had better ultrasonic velocity, as the voids are fewer, and the material is almost uniform.

- The microstructural analysis showed that for the specimens other than the PDSC, the 2-theta value was around 27; this shows the presence of silica $\left(\mathrm{SiO}_{2}\right)$ in the sample.

\section{Acknowledgment}

The authors would like to thank the Structural Engineering Laboratory and supporting staff, School of Civil Engineering; VIT University, Vellore for their support during the experimentation. 


\section{REFERENCES}

American Concrete Institute (ACI) (2007) Self-Consolidating Concrete, ACI 237R -07.

Choi, Y, W, - Kim, Y. J. - Shin, H, C. - Moon, H. Y. (2006) An experimental research on the fluidity and mechanical properties of high-strength lightweight self-compacting concrete. Cement and Concrete Research, Vol. 36, No. 9, pp.1595-1602.

EFNARC (2002) Specification and guidelines for self-consolidating concrete. European Federation of Producers and Applicators of Specialist Products for Structures, http://www.efnarc.org.

IS 383-1970. Specification for coarse and fine aggregates from natural sources of Concrete. Bureau of Indian Standards, New Delhi.

IS: 1903-1999. Concrete Admixture Specification, Bureau of Indian Standards. New Delhi.

IS: 516-1991. Methods of Tests for Strength of Concrete, Bureau of Indian Standards, New Delhi, India.

IS: 5816-1999. Splitting Tensile Strength of Concrete Method of Test, Bureau of Indian Standards, New Delhi, India.

IS: 13311 (part 1) -1992, Method of non-destructive testing for concrete; Methods of est, Bureau of Indian Standards, New Delhi.

Kanadasan, J-Razak, H, A. (2014) Mix design for self-compacting palm oil clinker concrete based on particle packing. Materials and Design Vol. 56, pp. 9-19.

Kim, Y. C. - Choi, Y. W. - Lachemi, M. (2010) Characteristics of self-Consolidating concrete using two types of lightweight coarse aggregates. Construction and Building Materials, vol. 24, pp.11-16.
Kwan, A. K. H., - Fung. W. W. S. (2009) Packing density measurement and modelling of fine aggregate and mortar. Cement and Concrete Composites, Vol. 31, No. 6, pp. 349 - 357.

Nanthagopalan, P. - Santhanam, M. (2012) An empirical approach for the optimisation of aggregate combinations for self-compacting concrete, Materials and Structures, Vol. 45, No. 8, pp. 1167 $-1179$

Priyadharshini P. - Ganesh, M. G. - Santhi, A. S. (2011) Experimental Study on Cold Bonded Fly Ash Aggregates. International Journal of Civil and Structural engineering, vol. 2, pp 493 -501.

Rodriguez de Sensale, G. - Rodriguez Viacava, I. - Aguado, A. (2015) Simple and Rational Methodology for the Formulation of Self-Compacting Concrete Mixes, Journal of Materials in Civil Engineering. Vol. 28, No.2, 04015116.

Su, N - Hsu, K. C. - Chai, H. W. (2001) A simple mix design method for self-compacting concrete. Cement and Concrete Research, vol. 31, pp. 1799-1807.

Su, N. - Miao, B. (2003) A new method for the mix design of medium strength flowing Concrete with low cement content. Cement and Concrete Research, vol. 25, pp. 215 -222.

Wua, Z - Zhang, Y. - Zheng, J. - Ding, Y. (2009) An experimental study on the workability of self-compacting lightweight concrete. Construction and Building Materials, vol. 23, pp. 2087-2092. 